\title{
PENGARUH FAMILY STRUCTURE TERHADAP MATERIALISME DAN PEMBELIAN KOMPULSIF PADA REMAJA
}

\author{
Ristianawati Dwi Utami (ristianawati@gmail.com) \\ Fakultas Ekonomi, Universitas Teknologi Yogyakarta
}

\begin{abstract}
The main issue of this study is how family structure influences on consumer behavior. In this study both family structure intact, disrupted family structure and family structure associated with the attitude of materialism and compulsive buying with family stressors and family resources as mediating variables and socioeconomic status as a moderating variable. The purpose of this study is (1) to determine differences in attitude of materialism and compulsive buying among teenagers who come from intact family with a disrupted family, (2) to measure the influence of family resources and family stressors on the attitude of materialism and compulsive buying in adolescents and (3) for measure the effect of family structure on family resources and family stressors when moderated by socioeconomic status variables. Samples of this study are adolescents aged 11-16 years who live in the city of Yogyakarta. Number of samples consisted of 97 teenagers who come from the intact family structure and 38 teenagers who come from disrupted family structure. The results showed that there were differences in the attitude of materialism and compulsive buying among teenagers who come from intact family with a disrupted family. Teenagers who come from disrupted family and compulsive tend to be more materialistic than adolescents from intact family. The study also found that family resources and family stressors shown to affect the materialism and compulsive buying in adolescents. Effect of family structure on family resources, moderated by socioeconomic status. While the influence of family structure on family stressors. Not moderated by socioeconomic status.
\end{abstract}

Keywords: Family Structure, Materialism, Compulsive Buying, Family Resources, Family Stressors.

\section{PENDAHULUAN}

Keluarga adalah sebuah lembaga sosial penting dalam masyarakat yang merupakan kelompok sosial pertama dalam kehidupan manusia, tempat seseorang melakukan proses pembelajaran dan menyatakan diri sebagai manusia sosial di dalam hubungan interaksi dengan kelompoknya. Keluarga mempunyai peranan yang sangat penting dalam membantu individu untuk melakukan proses sosialisasi melalui pembelajaran dan penyesuaian diri, dalam berfikir, bertindak, berperilaku dan bersikap secara baik di masyarakat. Termasuk di dalamnya ialah proses sosialisasi konsumen yang dimulai sejak anak-anak. Sosialisasi konsumen didefinisikan sebagai sebuah proses dimana individu akan memperoleh keahlian, pengetahuan dan sikap yang relevan dengan fungsi mereka sebagai konsumen di pasar (Ward,1974) dalam Lachance et al.,(2000). Dengan proses sosialisasi konsumen, anak-anak akan belajar tentang peranan pembelian dan konsumsi dari orang tuanya, mengamati bagaimana orang tua mereka mengevaluasi, memilih produk, dan melakukan proses pertukaran serta mempelajari bagaimana mereka akan membelanjakan uangnya dan bagaimana mereka akan berperilaku sebagai seorang konsumen.

Proses sosialisasi konsumen akan berjalan dengan baik pada sebuah keluarga yang utuh dan harmonis karena struktur keluarga yang utuh dan harmonis akan membawa dampak yang positif bagi perkembangan mental anak, sehingga hal tersebut akan sangat membantu bagi kesuksesan proses sosialisasi konsumen (Moschis, 1991). Akan tetapi seiring dengan adanya globalisasi, masyarakat juga dihadapkan pada perubahan demografi 
yang terjadi secara cepat dan dramatis, salah satunya ialah perubahan struktur keluarga. Masyarakat tidak hanya dihadapkan pada struktur keluarga yang utuh tetapi juga dihadapkan pada struktur keluarga yang tidak utuh yang hanya terdiri atas satu orang tua baik ayah atau ibu dalam sebuah keluarga atau single parent family structure. Perubahan struktur keluarga di masyarakat ini tampaknya sudah menjadi fenomena global. Di propinsi Daerah Istimewa Yogyakarta misalnya, kasus perceraian yang tercatat di Departemen Agama DIY berdasarkan data dari seluruh kantor Pengadilan Agama di DIY menunjukkan bahwa angka perceraian selalu meningkat dari tahun ke tahun. Pada tahun 2001 terdapat 1011 kasus perceraian, 1244 kasus perceraian pada tahun 2002 dan 1483 kasus perceraian pada tahun 2003 (Departemen Agama DIY, 2004).

Meskipun terdapat perubahan struktur keluarga yang cukup cepat, ternyata sampai saat ini masih sedikit penelitian pemasaran yang mencoba mengangkat issu tentang bagaimana berbagai alternatif bentuk struktur keluarga tersebut mempengaruhi perilaku konsumen. Menurut Eckel (1999) dalam Lachance et al. (2000), banyak peneliti dalam sosialisasi konsumen maupun perilaku konsumen atau bahkan kalangan pebisnis yang tampaknya mengabaikan studi tentang single-parent maupun nontradisional family. Sebagian besar penelitian pemasaran tentang perilaku konsumen atau family decision making masih didasarkan pada sebuah keluarga yang utuh atau intact family, sedangkan penelitian yang didasarkan pada sebuah keluarga yang tidak utuh atau single parent family sampai saat ini belum banyak dilakukan (Ahuja dan Stinson, 1993; Rindfleisch et al., 1997; dan Roberts et al., 2003).

Dengan demikian penelitian ini mencoba meneliti bagaimana fenomena perubahan struktur keluarga tersebut berpengaruh terhadap sikap dan perilaku konsumen. Dalam penelitian ini struktur keluarga dihubungkan dengan sikap materialisme dan pembelian kompulsif. Sikap materialisme dan konsumsi kompulsif digunakan sebagai konstruk pada penelitian karena: 1) kedua konstruk tersebut merupakan produk penting dari consumer culture (Belk, 1985; O’Quin dan Faber dan, 1989; Hischman, 1992; Faber dan O'Quin, 1992; Richins dan Dawson, 1992); 2) baik literature perilaku konsumen maupun sosiologi keluarga memberikan dasar yang kuat bahwa kedua konstruk tersebut berhubungan dengan struktur keluarga yang tidak utuh. Adapun tujuan dari penelitian adalah:

1. Mengukur perbedaan sikap materialisme dan pembelian kompulsif antara remaja yang berasal dari intact family structure dengan disrupted family structure.

2. Mengukur pengaruh family resources dan family stressors terhadap sikap materialisme pada remaja

3. Mengukur pengaruh family resources dan family stressors terhadap pembelian kompulsif pada remaja.

4. Mengukur pengaruh family structure terhadap family resources dan family stressors apabila dimoderasi oleh variabel status sosial ekonomi.

\section{LANDASAN TEORI DAN PENGEMBANGAN HIPOTESIS}

\section{Pengertian Materialisme}

Menurut Rich dan Dawson (1992) yang dimaksud dengan materialisme ialah sekumpulan keyakinan tetang pentingnya kepemilikan di dalam kehidupan seseorang. Keyakinan ini merupakan manifestasi dari tingkat dimana kepemilikan materi merupakan sumber utama dari kepuasan dan ketidakpuasan seseorang dalam hidupnya (Rindfleisch et al., 1997).

Beberapa peneliti pemasaran melihat materialisme sebagai "sisi gelap" dari perilaku konsumen. Menurut Belk (1985) materialisme berhubungan erat dengan tiga dimensi yaitu: kepemilikan (possessiveness), ketidakdermawanan (nongenerosity) dan kecemburuan (invy). Sedangkan Richins dan Dawson (1997) menilai bahwa nilai - nilai material dihubungkan dengan kepercayaan diri yang rendah, ketidakpuasan dengan kehidupan, dan 
ketidakpuasan dengan penghasilan yang tinggi. Jadi materialisme merupakan keyakinan utama individu bahwa uang, kepemilikan, dan kekayaan dipertimbangkan sebagai sesuatu yang relatif tinggi dan menonjol dalam kehidupan seseorang dibandingkan dengan penerimaan diri, persahabatan serta rasa kemanusiaan.

\section{Pembelian Kompulsif}

Menurut O'Quinn dan Faber (1989) pembelian kompulsif merupakan salah satu bentuk konsumsi kompulsif yaitu pembelian yang kronik dan repetitif yang terjadi sebagai respon dari perasaan atau kejadian yang negatif. Dalam melakukan proses pembelian, motivasi pembeli kompulsif adalah sebagai sarana untuk meningkatkan harga dirinya daripada untuk mengambil manfaat dan nilai - nilai ekonomis dari pembelian tersebut (O'Quinn dan Faber, 1989). O'Quinn dan Faber (1989) mendefinisikan konsumsi kompulsif sebagai respon dari keinginan atau dorongan yang tidak terkendali untuk mendapatkan, menggunakan atau memahami perasaan, hakekat atau aktivitas yang menjadi petunjuk seseorang untuk secara berulang melakukan perilaku yang dapat mencelakai seseorang atau orang lain. Menurur Hirschman (1992), konsumsi kompulsif sering dikaitkan dengan konsumsi alkohol atau obat- obat terlarang, kekerasan fisika dan koflik emosional seperti perceraian dalam keluarga.

\section{Struktur Keluarga dan Materialisme}

Kecenderungan bersikap materialistis pada remaja sering terjadi dalam situasi dimana seseorang kekurangan bimbingan orang tua dan kurangnya ketersediaan materi yang cukup (Moschis, 1987). Jadi kepemilikan materi sering diartikan sebagai pengganti dari ketidaktersediaan atau ketidakpuasan dalam hubungan antar personal sehingga individu yang materialistis lebih menekankan kepemilikan daripada hubungan antar personal (Belk, 1985; Richins 1994).

Dari kedua pandangan tersebut dapat ditarik kesimpulan yang sama. Ketidakharmonisan komunikasi yang biasanya menyertai perceraian dalam keluarga biasanya juga mempengaruhi proses sosialisasi pada anak-anak. Anak-anak yang dibesarkan dalam keluarga yang kacau jarang melakukan komunikasi dengan orang tuanya sehingga kurang mendapatkan sosialisasi dalam aktifitas konsumsi dan cenderung lebih materialistis daripada anak - anak yang dibesarkan pada keluarga yang harmonis (Moore dan Maoschis, 1981 dalam Rindfleisch et al., 1997). Jadi anak-anak atau remaja yang berasal dari keluarga yang kacau mungkin mendasarkan dirinya pada kepemilikan atau bersikap materialistis untuk menjembatani kesenjangan fisik antara dirinya dengan ketidakhadiran orang tua. Atas dasar pemikiran tersebut maka dikembangkan hipotesis sebagai berikut:

Hla: Remaja yang berasal dari disrupted families akan lebih materialistis daripada remaja yang berasal dari intact families.

Beberapa penelitian terdahulu juga menyatakan bahwa anak yang berasal dari singleparent family mempunyai kecenderungan yang besar untuk melakukan tindakan kompulsif dan disfungsional seperti mengkonsumsi alkohol, berjudi, hamil muda dan kriminalitas dibandingkan dengan anak - anak yang dibesarkan dalam two-parent family (Cherlin 1992; Fuchs 1983; Mcnalahan dan Booth 1989; Wu dan Martinson 1993 dalam Rindfleisch et al., 1997). Hampir sama dengan materialisme, konsumsi kompulsif juga merupakan manifestasi dari kurangnya kasih sayang dan bimbingan orang tua pada keluarga yang tidak utuh (Rindfleisch et al., 1997). Atas dengan dasar pemikiran tersebut maka dikembangkan hipotesis sebagai berikut:

H1b: Remaja yang berasal dari disrupted families akan menunjukkan kecenderungan yang besar dalam pembelian kompulsif daripada lebih remaja yang berasal dari intact families. 
Family Resources dan Family Stressors Hypothesis

Sumberdaya keluarga (family resources) adalah semua asset baik yang bersifat tangible maupun intangible di dalam keluarga yang digunakan untuk membesarkan anak-anak. Kedua bentuk family resources ini berhubungan satu sama lain. Dalam keluarga yang tidak utuh karena sumber pendapatan keluarga hanya berasal dari satu pihak maka orang tua tunggal cenderung berkonsentrasi untuk mencari penghasilan untuk menutupi kebutuhan mereka. Sehingga mereka lebih banyak menghabiskan waktu di tempat kerja. Hal ini tentu saja berdampak pada ketidaktersediaan orang tua di dekat anak yang mengakibatkan anak-anak kekurangan akan kasih sayang dan dukungan dari orang tua. Kurangnya family resources baik yang tangible maupun intagible pada anak-anak dari keluarga yang tidak utuh akan meningkatkan perilaku yang disfungsional dalam kehidupan mereka seperti materialisme dan pembelian kompulsif (Rindfleisch et al., 1997).

Family stressors merupakan bentuk tekana-tekanan dalam keluarga yang akan berpengaruh terhadap anggota keluarga. Anak-anak yang hidup dalam keluarga yang mengalami gangguan (disruption) seperti perceraian, perpisahan dan lain sebagainya akan mengalami sejumlah kejadian yang membuat mereka stress (Amoto, 1993). Keluarga yang tidak utuh mempunyai tingkat family stressors yang cukup tinggi jika hal tersebut tidak ditangani dengan cara yamg baik maka akan menciptakan sikap yang dekstruktif dan kompulsif (Aneshensel, 1992; Hodges, 1990 dalam Rindfleisch et al., 1997). Stress yang terjadi akibat perceraian dalam sebuah keluarga akan berpengaruh pada perkembangan mental anak-anak seperti harga diri yang rendah, hubungan interpersonal yang tidak baik, dan lain - lain (Haldnack 1992; Young dan Parish 1977 dalam Rindfleisch et al., 1997). Berdasarkan bukti - bukti penelitian terdahulu maka family stressors dapat berpengaruh terhadap sikap materialisme dan pembelian kompulsif. Atas dasar pemikiran tersebut maka dikembangkan hipotesis sebagai berikut:

H2: Family resources dan family stressors berpengaruh terhadap sikap materialisme pada remaja.

H3: Family resources dan family stressors berpengaruh terhadap pembelian kompulsif pada remaja.

\section{Status Sosial Ekonomi sebagai Variabel Moderator}

Keadaan sosial-ekonomi keluarga mempunyai peranan penting dalam perkembangan anak-anak. Efek yang merugikan dari keluarga yang tidak utuh pada anak - anak dan remaja adalah karena adanya kesenjangan dalam status sosio-ekonomi antara two-parent family dengan single -parent family (Cherlin 1992; McLanahan 1985; Mcnalahan dan Booth 1989; Thompson et al., 1992 dalam Rindfleisch et al., 1997). Jadi secara umum, para peneliti keluarga menyatakan bahwa status sosial-ekonomi dapat mempengaruhi hubungan antara struktur keluarga dengan efek - efek yang merugikan. Atas dasar pemikiran tersebut dikembangkan hipotesis sebagai berikut:

H4a: Pengaruh family structure pada family resources akan dimoderasi oleh status sosial ekonomi. Pengaruh Family Structure pada family resources akan kuat pada keluarga dengan status sosial ekonomi rendah daripada keluarga dengan status sosial ekonomi tinggi.

H4b: Pengaruh family structure pada family stressors akan dimoderasi oleh status sosial ekonomi. Pengaruh family structure pada family stressors akan kuat pada keluarga dengan status sosial ekonomi rendah daripada keluarga dengan status sosial ekonomi tinggi.

Berdasarkan landasan teori dan pengembangan hipotesis, maka model penelitian dapat digambarkan sebagai berikut: 


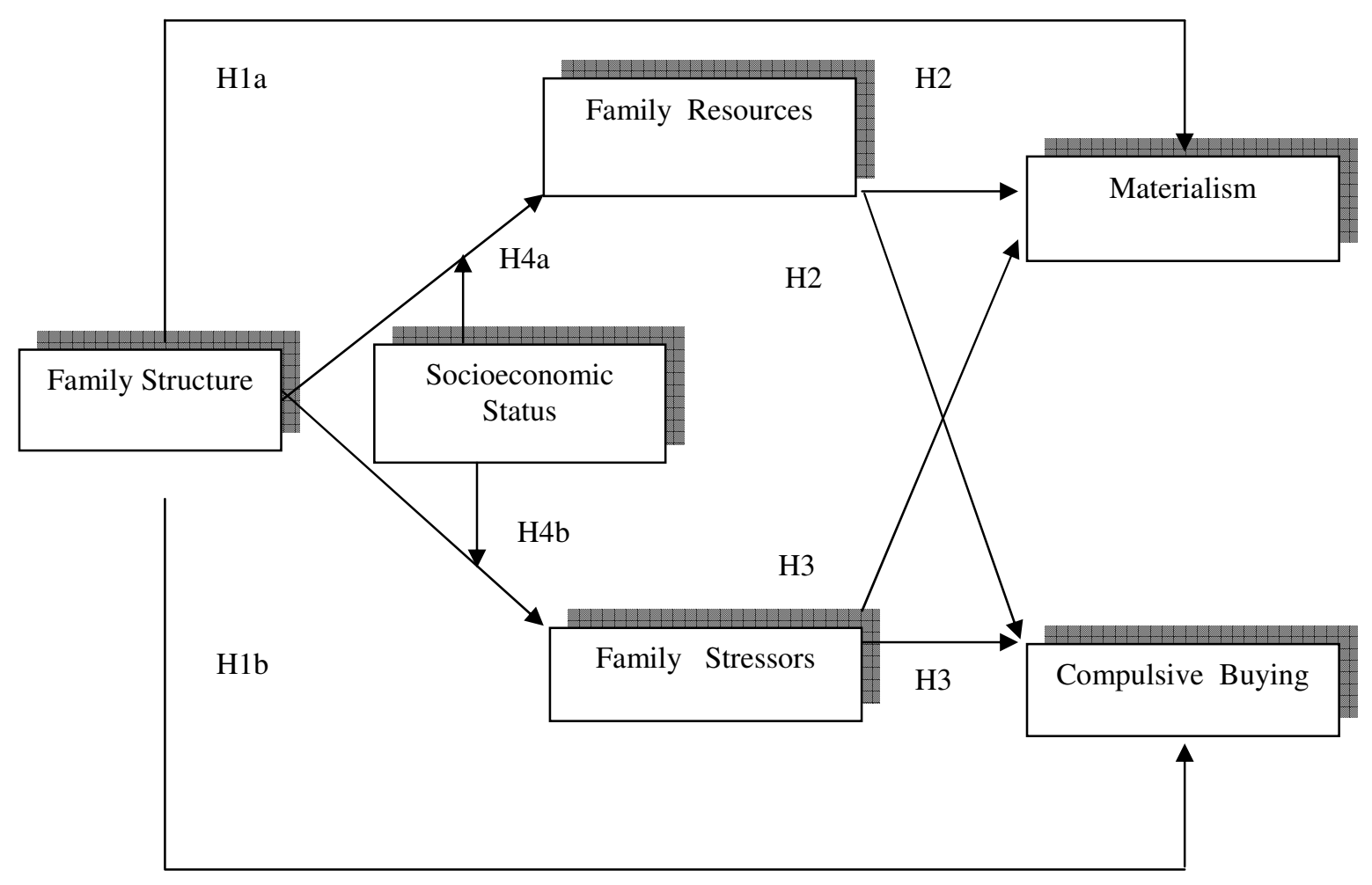

Gambar 1. Model Penelitian

\section{DATA DAN METODOLOGI}

Populasi dalam penelitian ini ialah remaja berusia 11-16 tahun yang berasal dari keluarga bercerai maupun tidak bercerai dan berdomisili di Kotamadya Yogyakarta. Metode sampling yang digunakan dalam penelitian ialah purposive sampling. Kriteria sampel yang digunakan dalam penelitian ini ialah remaja korban perceraian maupun bukan korban perceraian dan berusia antara 11-16 tahun. Penyebaran kuesioner dilakukan dengan dua cara yaitu: 1) bagi remaja korban perceraian penyebaran kuesioner dengan cara datang langsung ke rumah responden korban perceraian, data alamat responden diperoleh dari Pengadilan Agama Yogyakarta, 2) penyebaran kuesioner melalui beberapa SMP dan SMU di Kotamadya Yogyakarta baik untuk anak korban perceraian maupun bukan korban perceraian.

Partisipan dalam penelitian ini ialah 135 remaja, terdiri dari 97 remaja berasal dari intact family dan 38 remaja berasal dari disrupted family. Berdasarkan tingkat status sosial ekonomi, 85 remaja $(63,0 \%)$ di antaranya berasal dari keluarga yang status sosial ekonominya rendah atau kurang baik, dan 50 remaja $(37,0 \%)$ berasal dari keluarga yang status sosial ekonominya tinggi atau baik. Hipotesis la dan $1 \mathrm{~b}$ diuji dengan teknik independent sample t-test. Pengujian dilakukan dengan cara membandingkan perbedaan antara dua nilai rata-rata dengan standard error dari perbedaan rata-rata dua sampel, dalam hal ini anak yang berasal dari keluarga utuh (intact family) dan anak yang berasal dari keluarga yang mengalami gangguan perceraian (disrupted family) dikelompokkan menjadi dua berdasarkan family structure. Analisis regresi berganda digunakan untuk menguji hipotesis 2 dan hipotesis 3 . ANOVA dua arah digunakan untuk menguji hipotesis $4 a$ dan $4 b$. Hipotesis $4 a$ dan $4 b$, mengukur pengaruh family structure pada family resources dan family stressors apabila dimoderasi oleh status sosial ekonomi. Sebelum melakukan analisis ini terlebih dahulu dilakukan pengelompokan sampel variabel bebas. Variabel family structure terdiri atas dua kelompok yaitu intact family dan disrupted family. Sedangkan satus sosial 
ekonomi juga terdiri atas dua kelompok yaitu status sosial ekonomi rendah dan status sosial ekonomi tinggi.

\section{HASIL PENELITIAN}

\section{Pengujian Hipotesis 1}

Pengujian hipotesis la menunjukkan hasil yang signifikan antara sikap materialisme remaja yang berasal dari intact family maupun disrupted family dengan nilai $p(0,000)<a(0,05)$. Remaja yang berasal dari disrupted family dipersepsikan lebih materialistis daripada remaja yang berasal dari intact family dengan rerata masing-masing 3,164 dan 2,538. Hasil pengujian hipotesis la dapat dilihat pada tabel 1 berikut.

Tabel 1. Uji † Perbedaan Materialism

\begin{tabular}{|l|c|c|c|c|}
\hline \multirow{2}{*}{ Family Structure } & \multicolumn{2}{|c|}{ Materialism } & \multirow{2}{*}{$\dagger$} & \multirow{2}{*}{$\mathrm{P}$} \\
\cline { 2 - 3 } & $\overline{\mathrm{X}}$ & $\mathrm{SD}$ & & \multirow{2}{*}{0,000} \\
\hline Tidak utuh (Disrupted family) & 3,1637 & 0,5932 & \multirow{2}{*}{6,223} & \multirow{2}{*}{0,000} \\
Utuh (Intact family) & 2,5384 & 0,4963 & &
\end{tabular}

Sumber: Data primer diolah

Hipotesis $1 \mathrm{~b}$ penelitian ini menduga bahwa remaja yang berasal dari keluarga yang tidak utuh (disrupted familiy) memiliki compulsive buying lebih kuat dibanding dengan remaja yang berasal dari keluarga utuh (intact family). Dengan nilai $p(0,000)<a(0,05)$, skor rerata maing-masiang ialah 3,9632 dan 2,6536 . Hasil pengujian hipotesis $1 \mathrm{~b}$ dapat dilihat pada tabel 2 berikut.

Tabel 2. Uji † Perbedaan Compulsive Buying

\begin{tabular}{|l|c|c|c|c|}
\hline \multirow{2}{*}{ Family Structure } & \multicolumn{2}{|c|}{ Compulsive Buying } & \multirow{2}{*}{$\dagger$} & \multirow{2}{*}{$\mathrm{P}$} \\
\cline { 2 - 3 } & $\overline{\mathrm{X}}$ & $\mathrm{SD}$ & & \\
\hline Tidak utuh (Disrupted family) & 3,9632 & 1,6655 & \multirow{2}{*}{6,756} & \multirow{2}{*}{0,000} \\
\hline
\end{tabular}

Sumber: Data primer diolah

Pengujian Hipotesis 2

Hipotesis 2 penelitian ini menduga bahwa family resources dan family stressors berpengaruh terhadap sikap materialisme. Pengujian hipotesis 2 menggunakan analisis regresi berganda. Adapun hasil analisis regresi untuk menguji hipotesis tersebut disajikan dalam tabel 3 berikut:

Tabel 3. Hasil Analisis Regresi Berganda

Pengaruh Family Resource dan Family Stressor terhadap Materialism

\begin{tabular}{|l|c|c|c|}
\hline \multicolumn{1}{|c|}{ Variabel Bebas } & $\beta$ & $\dagger$ & $\mathrm{P}$ \\
\hline Family Resource & $-0,202$ & $-2,227$ & 0,028 \\
Family Stressor & 0,129 & 1,415 & 0,159 \\
\hline Rªdjusted $=0,064$ & \\
F=5,586 $\mathrm{p}=0,05$
\end{tabular}

Sumber: Data primer diolah

Berdasarkan hasil analisis regresi yang disajikan dalam tabel 3 tampak bahwa pengaruh family resource terhadap materialisme mempunyai nilai $p=0,028$. Sehingga secara individu family resources berpengaruh terhadap materialisme. Diketahui bahwa koefisien beta family resources bertanda negatif $(-0,202)$, ini berarti bahwa semakin besar family resources maka tingkat materialisme remaja akan semakin kecil. Pengaruh family stressor terhadap 
materialisme mempunyai nilai $\mathrm{p}=0,159$. Sehingga family stressor secara individu tidak berpengaruh terhadap materialisme.

Pengujian Hipotesis 3

Hipotesis 3 penelitian ini menduga bahwa pengaruh family resources dan family stressors berpengaruh terhadap compulsive buying. Adapun hasil analisis regresi untuk menguji hipotesis tersebut disajikan dalam tabel 4 berikut:

Tabel 4. Hasil Analisis Regresi

Pengaruh Family Resources dan Family Stressors Terhadap Compulsive Buying

\begin{tabular}{|l|c|c|c|}
\hline \multicolumn{1}{|c|}{$\begin{array}{c}\text { Variabel } \\
\text { Independen }\end{array}$} & $\beta$ & $\dagger$ & $\mathrm{p}$ \\
\hline Family Resource & $-0,223$ & $-2,586$ & 0,011 \\
Family Stressor & 0,270 & 3,128 & 0,002 \\
\hline R$^{2}$ adjusted $=0,157$ & & \\
F=13,505; $\mathrm{p}=0,000$ &
\end{tabular}

Sumber: Data primer diolah

Berdasarkan hasil analisis regresi yang disajikan dalam tabel 4 tampak bahwa pengujian secara individu pengaruh family resource terhadap compulsive buying mempunyai nilai $p=0,011$. Sehingga family resource secara individu berpengaruh terhadap compulsive buying. Diketahui bahwa koefisien beta family resources bertanda negative $(-0,223)$, ini berarti bahwa semakin besar family resources maka tingkat pembelian kompulsif remaja akan semakin kecil. Pengaruh family stressor terhadap compulsive buying memiliki nilai $p=0,002$. Sehingga family stressor secara individu bepengaruh positif dan signifikan terhadap compulsive buying.

Pengujian Hipotesis $4 a$

Hipotesis 4a penelitian ini menduga bahwa pengaruh family structure pada family resources apabila dimoderasi oleh status sosial ekonomi. Pengujian terhadap hipotesis ini dilakukan dengan menggunakan analysis of variance (ANOVA) dua arah atau ANOVA two factorial design. Adapun ringkasan hasil ANOVA tersebut disajikan dalam table 5 berikut:

Tabel 5. Hasil ANOVA Dua Arah

\begin{tabular}{|l|r|r|}
\hline \multicolumn{1}{|c|}{$\begin{array}{c}\text { Variabel } \\
\text { Independen }\end{array}$} & \multicolumn{1}{c|}{$\mathrm{F}$} & $\mathrm{p}$ \\
\hline Family structure (FS) & 77,156 & 0,000 \\
Social Economic Status (SES) & 4,687 & 0,032 \\
Interaction FSxSES & 9,351 & 0,003 \\
\hline
\end{tabular}

Sumber: Data primer diolah

Berdasarkan hasil ANOVA dua arah di atas tampak bahwa faktor interaksi FS $\times$ SES memiliki $F=9,351$ dengan $p=0,003$. Pada tingkat signifikansi $a=0,05$ apabila nilai $p(0,003)<a(0,05)$ maka pengaruh faktor interaksi FSxSES tersebut signifikan. Dengan demikian dapat disimpulkan bahwa pengaruh family structure pada family resources secara signifikan dimoderasi oleh status sosial ekonomi, sehingga hipotesis 4 a penelitian didukung oleh data penelitian ini, atau dengan kata lain hipotesis $4 a$ dalam penelitian ini diterima. Deskriptif statistik uji ANOVA dua arah dapat dilihat pada berikut:

Tabel 6. Deskriptif Statistik Uji ANOVA Dua Arah

Dependen Variabel : Family Resources 


\begin{tabular}{|l|l|c|c|c|}
\hline Family Structure & Social Economic Status & Mean & SD & $\mathrm{N}$ \\
\hline intact family & rendah & 4,2112 & 0,4003 & 58 \\
& tinggi & 4,1122 & 0,5581 & 39 \\
\hline disrupted family & rendah & 2,8981 & 0,7516 & 27 \\
& tinggi & 3,4773 & 0,4535 & 11 \\
\hline
\end{tabular}

Berdasarkan tabel 6 tampak bahwa mean (rata-rata) kelompok intact family lebih besar dari kelompok disrupted family. Dengan demikian dapat disimpulkan bahwa tingkat family resources lebih besar didapatkan oleh remaja yang berasal dari intact family daripada remaja yang berasal dari disrupted family. Untuk melihat perbedaan family resources antar kelompok maka dilakukan prosedur perbandingan berganda (pair comparison). Dalam Pair Comparison terdapat 4 kategori yang akan diperbandingkan yaitu intact family SES rendah, intact family SES tinggi, disrupted family SES rendah, dan disrupted family SES tinggi.

Perbandingan antar kategori yang akan dilakukan ialah antara kategori 1-2, 1-3, 1-4, 2-3, 24, dan 3-4. Jadi secara keluruhan terdapat 6 perbandingan antar kategori untuk melihat tingkat family resources. Hasil pair comparison antar kategori dapat dilihat pada table 7 berikut

Tabel 7. Pair Comparison Family Resource

\begin{tabular}{|c|l|c|c|c|c|c|}
\hline $\begin{array}{c}\text { Variabel } \\
\text { Independen }\end{array}$ & \multicolumn{1}{|c|}{$\begin{array}{c}\text { Perbandingan antar } \\
\text { Kategori }\end{array}$} & $\mathbf{N}$ & Mean & $\begin{array}{c}\text { Mean } \\
\text { Diff. }\end{array}$ & $\mathbf{t}$ & $\mathbf{p}$ \\
\hline Family & Intact SES Rendah (1) & 58 & 4,2112 & 0,9903 & 0.955 & 0.343 \\
Resources & Intact SES Tingai (2) & 39 & 4,1122 & & & \\
\cline { 2 - 7 } & Intact SES Rendah (1) & 58 & 4,2112 & 1,3131 & 8.532 & 0.000 \\
& Disrupted SES Rendah (3) & 27 & 2,8981 & & & \\
\cline { 2 - 7 } & Intact SES Rendah (1) & 58 & 4,2112 & 0,7739 & 5.461 & 0.000 \\
& Disrupted SES Tingai (4) & 11 & 3,4773 & & & \\
\cline { 2 - 7 } & Intact SES Tinggi (2) & 39 & 4,1122 & 1,2141 & 7.532 & 0.000 \\
\cline { 2 - 7 } & Disrupted SES Rendah (3) & 27 & 2,8981 & & & \\
\cline { 2 - 7 } & Intact SES Tinggi (2) & 39 & 4,1122 & 0,6349 & 3.457 & 0.001 \\
& Disrupted SES Tinggi (4) & 11 & 3,4773 & & & \\
\cline { 2 - 7 } & Disrupted SES Rendah (3) & 27 & 2,8981 & $-0,5791$ & -2.374 & 0.023 \\
& Disrupted SES Tinggi (4) & 11 & 3,4773 & & & \\
\hline
\end{tabular}

Berdasar uji pair comparison family resources tampak bahwa terdapat perbedaan yang signifikan, tingkat family resources antar kategori. Dengan $\mathrm{p}(0,343)>0.05$ maka tidak terdapat perbedaan yang signifikan, tingkat family resources antara intact family SES rendah dengan intact family SES tinggi. Dari uji tersebut dapat dianalisis bahwa tingkat family resources disrupted family SES tinggi ( $\bar{X}=3,4773$ ) tetap lebih rendah daripada family resources intact family SES rendah $(\bar{X}=4,2112)$ maka dapat disimpulkan bahwa remaja yang berasal dari intact family dengan SES rendah maupun SES tinggi tetap mendapatkan family resources yang lebih daripada remaja yang berasal dari disrupted family. Tingkat family resources terendah diperoleh remaja yang berasal dari disrupted family dengan SES rendah $(\overline{\mathrm{X}}=2,8981)$.

Pengujian Hipotesis $4 b$

Hipotesis 4a penelitian ini menduga bahwa pengaruh family structure pada family stressor dimoderasi oleh status sosial ekonomi. Pengujian terhadap hipotesis ini dilakukan dengan menggunakan analisis varian faktorial. Adapun ringkasan hasil ANOVA dua arah dapat dilihat pada tabel 8 berikut: 


\begin{tabular}{|l|c|c|}
\hline \multicolumn{1}{|c|}{ Variabel Independen } & $\mathrm{F}$ & $\mathrm{P}$ \\
\hline Family structure (FS) & 3,105 & 0,080 \\
Social Economic Status (SES) & 1,779 & 0,185 \\
Interaction FSxSES & 0,058 & 0,810 \\
\hline
\end{tabular}

Berdasarkan hasil analisis ANOVA dua arah di atas tampak bahwa pengaruh faktor interaksi FS $\times$ SES memiliki $F=0,058$ dengan $p=0,810$ Pada tingkat signifikansi $a=0,05$ apabila nilai $p(0,810)>a(0,05)$ maka pengaruh faktor interaksi FS $\times S E S$ tersebut tidak signifikan. Dengan demikian dapat disimpulkan bahwa pengaruh family structure pada family stressor tidak dimoderasi oleh status sosial ekonomi, sehingga hipotesis $4 b$ penelitian tidak didukung oleh data penelitian ini, atau dengan kata lain hipotesis $4 b$ penelitian ini tidak diterima.Deskriptif statistik uji ANOVA dua arah dapat dilihat pada table 9 berikut:

Tabel 9. Deskriptif Statistik Uji ANOVA Dua Arah

Dependen Variabel: Family Stressors

\begin{tabular}{|l|c|c|c|c|}
\hline Family Structure & $\begin{array}{c}\text { Social Economic } \\
\text { Status }\end{array}$ & Mean & SD & N \\
\hline intact family & rendah & 2,4993 & 0,6229 & 58 \\
& tinggi & 2,2926 & 0,5856 & 39 \\
disrupted family & rendah & 2,2363 & 0,6858 & 27 \\
& tinggi & 2,0927 & 0,3278 & 11 \\
\hline
\end{tabular}

Berdasarkan tabel 9 tampak bahwa tidak terdapat perbedaan mean yang cukup signifikan antara intact family dengan disrupted family. Untuk melihat perbedaan family stressors antar kategori maka dilakukan prosedur perbandingan berganda (pair comparison). Dalam Pair Comparison terdapat 4 kategori yang akan diperbandingkan yaitu intact family SES rendah, intact family SES tinggi, disrupted family SES rendah, dan disrupted family SES tinggi.

Perbandingan antar kategori yang akan dilakukan ialah antara kategori 1-2,1-3,1-4 2-3, 2-4, dan 3-4. Jadi secara keluruhan terdapat 6 perbandingan antar kategori untuk melihat tingkat family stressors. Hasil pair comparison antar kategori dapat dilihat pada tabel 10 berikut ini :

Tabel 10. Pair Comparison Family Stressor

\begin{tabular}{|c|l|c|c|c|c|c|}
\hline $\begin{array}{c}\text { Variabel } \\
\text { Independen }\end{array}$ & \multicolumn{1}{|c|}{$\begin{array}{c}\text { Perbandingan antar } \\
\text { Kategori }\end{array}$} & $\mathrm{N}$ & Mean & $\begin{array}{c}\text { Mean } \\
\text { Diff. }\end{array}$ & $\dagger$ & $\mathrm{p}$ \\
\hline $\begin{array}{c}\text { Family } \\
\text { Stressors }\end{array}$ & Intact SES Rendah (1) & 58 & 2,4993 & 0,2067 & 1,546 & 0,125 \\
& Intact SES Tingai (2) & 39 & 2,2926 & & & \\
\cline { 2 - 7 } & Intact SES Rendah (1) & 58 & 2,4993 & 0,2630 & 1,651 & 0,103 \\
& Disrupted SES Rendah & 27 & 2,2363 & & & \\
\cline { 2 - 7 } & Intact SES Rendah (1) & 58 & 2,4993 & 0,4066 & 1,924 & 0.059 \\
& Disrupted SES Tingai (4) & 11 & 2,0927 & & & \\
\cline { 2 - 7 } & Intact SES Tinggi (2) & 39 & 2,2926 & 0,0563 & 0,358 & 0,722 \\
& Disrupted SES Rendah & 27 & 2,2363 & & & \\
\cline { 2 - 7 } & Intact SES Tinggi (2) & 39 & 2,2926 & 0,1999 & 1,080 & 0,286 \\
& Disrupted SES Tingai (4) & 11 & 2,0927 & & & \\
\cline { 2 - 8 } & Disupted SES Rendah & 27 & 2,2363 & $-0,1436$ & 0,660 & 0,513 \\
& Disrupted SES Tinggi (4) & 11 & 2,0927 & & & \\
\hline
\end{tabular}

Berdasar uji pair comparison tersebut tampak bahwa semua nilai probabilitas lebih besar dari tingkat signifikansi 0,05 sehingga tidak terdapat perbedaan tingkat family stressors yang cukup signifikan antar kategori. Hal ini konsisten dengan hasil uji $F$ dimana status sosial ekonomi tidak memoderasi hubungan family structure pada family stressors. Sehingga dapat disimpulkan bahwa family stressors dialami oleh semua remaja baik dari status sosial ekonomi rendah maupun tinggi. 


\section{PEMBAHASAN}

Hasil penelitian ini membuktikan bahwa family structure berpengaruh terhadap materialisme dan pembelian kompulsif. Hipotesis la membuktikan bahwa sikap materialisme remaja yang berasal dari keluarga yang tidak utuh (disrupted family) lebih kuat dibanding dengan sikap materialisme pada remaja dari keluarga utuh (intact family). Hasil tersebut dapat dilihat di tabel 3 dimana remaja yang berasal dari disrupted family mempunyai $\bar{X}=3,1637$ sedangkan yang berasal dari intact family mempunyai $\bar{X}=2,5384$. Hasil penelitian ini konsisten dengan hasil penelitian-penelitian sebelumnya. Sebagai contoh, penelitian yang dilakukan Rindfleisch et al. (1997) juga menemukan bahwa family structure berpengaruh terhadap materialisme dan pembelian kompulsif. Dan terdapat berbedaan sikap materialisme antara remaja yang berasal dari disrupted family dengan intact family.

Hipotesis 1b membuktikan bahwa pembelian kompulsif remaja yang berasal dari keluarga yang tidak utuh (disrupted family) lebih kuat dibanding dengan pembelian kompulsif pada remaja dari keluarga utuh (intact family). Dimana remaja yang berasal dari disrupted family mempunyai $\bar{X}=3,9632$ sedangkan yang berasal dari intact family mempunyai $\bar{X}=2,6536$. Menurut O'Quinn dan Faber (1989) pembelian kompulsif merupakan salah satu bentuk konsumsi kompulsif yaitu pembelian yang kronik dan repetitif yang terjadi sebagai respon dari perasaan atau kejadian yang negatif. Beberapa penelitian terdahulu juga menyatakan bahwa remaja yang berasal dari single-parent family mempunyai kecenderungan yang besar untuk melakukan tindakan kompulsif dan disfungsional seperti mengkonsumsi alkohol, berjudi, hamil muda dan kriminalitas dibandingkan dengan anak - anak yang dibesarkan dalam two-parent family (Cherlin 1992; Fuchs 1983; Mcnalahan dan Booth 1989; Wu dan Martinson 1993 dalam Rindfleisch et al., 1997). Temuan ini relevan dengan penemuan Hirschman (1992) dan Rook (1987) dalam Rindfleisch et al. (1997) bahwa terdapat hubungan antara tumbuh atau dibesarkan dalam disrupted family dengan kecenderung untuk berperilaku impulsif dan kompulsif.

Berdasar hasil analisis regresi untuk menguji hipotesis 2 , tampak bahwa dengan $p=0,028$ dan $\beta=-0,202$ maka family resources secara signifikan berpengaruh negatif terhadap sikap materialisme. Koefisien beta family resources bertanda negatif ini berarti bahwa semakin besar family resources maka tingkat materialisme remaja akan semakin kecil. Menurut Rindfleisch et al. (1997), kurangnya family resources baik yang tangible maupun intagible pada remaja akan meningkatkan perilaku yang disfungsional dalam kehidupan mereka seperti materialime dan pembelian kompulsif. Pengaruh family stressor terhadap materialism memiliki nilai $\mathrm{p}=0,159$ sehingga family stressor tidak berpengaruh terhadap materialisme.

Hipotesis 3 penelitian ini membuktikan bahwa family resources dan family stressors berpengaruh terhadap compulsive buying. Hasil analisis regresi hipotesis 3 dengan $p=0.011$ dan $\beta=-0,223$ maka family resources secara signifikan berpengaruh negatif terhadap compulsive buying. Koefisien beta family resources bertanda negatif, ini berarti bahwa semakin besar family resources maka tingkat pembelian kompulsif remaja akan semakin kecil. Pengaruh family stressor terhadap compulsive buying memiliki nilai $p=0,002$ dan $\beta=$ 0,270 sehingga family stressor bepengaruh positif dan signifikan terhadap compulsive buying.

Hasil hipotesis 4a dalam penelitian ini konsisten dengan temuan Rindfleisch et al. (1997) dimana status sosial ekonomi merupakan faktor yang memoderasi hubungan antara family structure pada family resources. Penelitian-penelitian terdahulu dalam sosiologi keluarga menemukan bahwa status sosial ekonomi dalam taraf tertentu dapat melemahkan dampak negatif dari perceraian keluarga pada anak-anak dan remaja (Cherlin 1992; Fuchs 1983; Mcnalahan dan Booth 1989; Wu dan Martinson 1993 dalam Rindfleisch et al., 1997) Berdasarakn hasil ANOVA dua arah hipotesis 4 a dimana dari interaksi antara family structure dan status sosial ekonomi didapatkan nilai $F=9,351$ dengan $p=0,03$. Dari uji ANOVA dua arah juga terlihat bahwa remaja yang berasal dari disrupted family mendapatkan family 
resources yang lebih kecil dibandingkan dengan remaja dari intact family. Berdasar hasil pair comparison terlihat bahwa tingkat family resources paling rendah diperoleh remaja yang berasal dari disrupted family dengan status sosial ekonomi rendah $(\bar{X}=2,8981)$. Menurut Amato (1991) dalam Roberts at al. (2003), perceraian dapat mereduksi kuantitas dan kualitas hubungan antara anak dan orang tua. Remaja korban perceraian akan kekurangan intangible resources seperti perhatian, kasih sayang dan bimbingan orang tua. Tingkat pendapatan yang sering dihubungkan dengan status sosial ekonomi dapat menjadi petunjuk bagi kualitas dan kuantitas family resources yang diberikan orang tua kepada anak (Rindfleisch et al.,1997).

Hasil hipotesis 4b dalam penelitian ini konsisten dengan temuan Rindfleisch et al.,(1997) dimana tidak terbukti bahwa status sosial ekonomi merupakan faktor yang memoderasi hubungan antara family structure pada family stressors. Berdasar hasil ANOVA dua arah hipotesis $4 \mathrm{~b}$, dimana dari interaksi family structure dangan status sosial ekonomi diperoleh nilai $F=0,058$ dengan $p=0,810$. Menurut Rindfleisch et al.(1997) dan Roberts et al.(2003), status sosial ekonomi tidak memoderasi hubungan family structure pada family stressor karena family stressors relatif stabil dan dialami remaja dari berbagai macam strata status sosial ekonomi. Skala pengukuran family stressors yang terdiri dari kesulitan dalam menjaga hubungan dengan orang tua, saudara dan teman, kesulitan dalam pekerjaan sekolah juga mempengaruhi remaja dari berbagai macam strata status sosial ekonomi. Berdasar uji pair comparison tampak bahwa tidak terdapat perbedaan family stressor yang cukup signifikan antara remaja yang berasal dari disrupted family dengan status sosial ekonomi rendah-tinggi maupun intact family dengan status sosial ekonomi rendah-tinggi.

\section{KESIMPULAN DAN SARAN}

Kesimpulan

a. Family structure berpengaruh terhadap sikap materialisme pada remaja. Remaja yang berasal dari keluarga tidak utuh (disrupted familiy) memiliki materialism yang signifikan lebih kuat dibanding remaja dari keluarga utuh (intact family).

b. Family structure berpengaruh terhadap pembelian kompulsif pada remaja. Remaja yang berasal dari keluarga tidak utuh (disrupted familiy) memiliki compulsive buying yang signifikan lebih kuat dibanding remaja dari keluarga utuh (intact family).

c. Family resources dan family stressors berpengaruh terhadap materialisme dan pembelian kompulsif. Family resources adalah semua sumber daya keluarga baik yang bersifat tangible (uang, makanan, pakaian) maupun intangible (kasih sayang, perhatian dan bimbingan orang tua). Kurangnya family resources baik tangible maupun intangible dalam keluarga dapat meningkatkan perilaku yang disfungsional seperti materialisme dan pembelian kompulsif. Family stressors adalah tekanan-tekanan atau permasalahan dalam keluarga yang akan berpengaruh terhadap remaja. Family stressors yang cukup tinggi dapat menyebabkan sikap yang dekstruktif dan kompulsif.

d. Status sosial ekonomi memoderasi hubungan family structure pada family resources. Tingkat family resources terendah diperoleh remaja yang berasal dari disrupted family dengan status sosial ekonomi rendah. Remaja yang berasal dari intact family dengan status sosial ekonomi rendah maupun tinggi tetap mendapatkan family resources yang lebih daripada remaja yang berasal dari disrupted family. Remaja yang berasal dari disrupted family cenderung kekurangan intangible resources seperti kasih sayang, bimbingan dan teladan orang tua.

e. Status sosial ekonomi tidak memoderasi hubungan family structure pada family stressors. Status sosial ekonomi tidak memoderasi hubungan family structure pada family stressor karena family stressors juga dialami anak-anak dan remaja dari berbagai macam strata status sosial ekonomi. Skala pengukuran family stressors yang terdiri dari kesulitan dalam menjaga hubungan dengan orang tua, saudara dan teman, kesulitan dalam pekerjaan sekolah juga mempengaruhi remaja dari berbagai macam strata status sosial ekonomi. 
Saran

Berdasarkan hasil analisis seperti yang telah disampaikan, maka beberapa saran untuk penelitian yang lebih komprehensif di masa yang akan datang ialah:

a. Agar diperoleh hasil penelitian yang memiliki tingkat generalisasi yang tinggi, sebaiknya penelitian dilakukan di beberapa kota di Indonesia dengan ukuran sampel yang lebih besar sehingga hasil penelitian akan lebih berlaku umum dibanding hasil penelitian ini.

b. Penelitian di masa yang akan dapat dapat menggunakan usia responden yang berbeda untuk melihat ada tidaknya kesamaan sikap terhadap materialisme dan pembelian kompulsif dari sudut pandang usia.

c. Penelitian di masa yang akan datang juga perlu mempertimbangkan faktor-faktor seperti parental style, antecedents dalam perceraian keluarga, proses perceraian serta konsekuensi atau dampak dari perceraian terhadap perilaku konsumen.

\section{DAFTAR PUSTAKA}

Ahuja, Roshan and Kandi Stinson. (1993). Female headed single parent families: An exploratory study of children's nfluence in family decision making. Advances in Consumer Research, Vol 20, $469-474$.

Amato, Paul R. (1993). Children's adjustment to divorce: theories, hypotheses, and empirical support. Journal Marriage and the Family, 55 (February), 23-38.

Assael, H. (1998). Consumer Behavior and Marketing Action. 6th ed. Cincinnati, OH: SouthWestern College Publishing.

Belk, Russel W. (1985). Materialism: Trait aspects of living in the material world. Journal of Consumer Research, 12 (December), 265-280.

Cooper, Donald R, and Pamella S. Schindler. (2003). Business Research Methods. $8^{\text {th }}$ ed. New York: Mc Graw-Hill Company.

Faber, Ronald J. and Thomas C. O'Quinn. (1992). A clinical screener for compulsive buying. Journal of Consumer Research, 19 (December), 459-469

Hair, F.J. Jr, R.E. Anderson, R.L. tatham dan W.G. Black. (2006). Multivariate Data Analysis, $5^{\text {th }}$ ed. USA: Prentice Hall International Inc.

Hirschman, Elizabeth C. (1992). The coonsciouness of addition: Toward a general Theory of compulsive consumption. Journal of Consumer Research, 19 (September), 155-179.

Kourilsky, Murray. (1981). The use of Economic Reasoning to Increase Satisfaction with Family Decision Making. Journal of Consumer Research, 6 (September), 183 - 188.

Lachance, Legault and Bujold. (2000). Family structure, parent-child communication, and adolescent participation in family consumer tasks and decisions. Family and Consumer Sciences Research Journal. Vol 29 No. 2 (December), 125-152

McAlexander, James H., John W. Schouten, and Scott D Roberts. (1993). Consumer behavior and divorce. Research in Consumer Behavior, 153 - 184.

McLanahan and Karen Booth. (1989). Mother- only families: Problem, prospects and politcs. Journal of Marriage and The Family, 51(August), 557-580

Moschis, G. P. (1991). The role of family in consumer socialization of children and andolescent. Perpectives in Consumer Behavior, $4^{\text {the }}$ ed, 396-417.

Mowen and Minor (2001), Consumer Behavior, $5^{\text {th }}$ ed, Harcourt Inc. 
O'Quinn, Thomas C, and Ronald J. Faber. (1989). Compulsive buying: A phenomenological exploration, Journal of Consumer Research, 16 (September), 147-157

Richins, Marsha L. (1994). Spesial possessions and the expression of material values", Journal of Consumer Research, 21 (December), 522-533.

Richins, Marsha L and Scott Dawson. (1992). A consumer values orientation for materialism and its measurement: Scale development and validation. Journal of Consumer Research, 19 (December), 303-316.

Rindfleisch, Burroughs and Denton. (1997). Family structure, materialism and compulsive consumption. Journal of Consumer Research, 23 (March), 312-325.

Roberts, Manolis, and Tanner Jr. (2003). Family structure, materialism and compulsive buying,. Journal of Academy of Marketing Science, Vol 31, No 3, 300 - 311.

Singarimbun. (1989). Metode Penelitian Survai, Jakarta: LP2ES.

Soesilowindradini. (1988). Psikologi Perkembangan (Masa Remaja), Surabaya: Penerbit Usaha Nasional.

Wu, Lawrence L and Brian C. Martinson. (1993). Family structure and the riks of premarital births. American Sociological review, 58 (April), 210 - 232.

Yurchisins, Jeniffer and Kim K.P. Johnson. (2004). Compulsive buying behavior and Its relationship to perceived social status associated with buying, materialism, selfesteem, and apparel-product involvement. Family and Consumer Sciences Research Journal. Vol 32 No. 3 (March), 291-134 